\title{
Association of Body Composition and Aerobic Fitness on Heart Rate Variability and Recovery in Young-Adult Black Men
}

\author{
Michael R. Esco ${ }^{1}$, Robert L. Herron ${ }^{2}$, Stephen J. Carter ${ }^{2}$, Andrew A. Flatt ${ }^{1}$ \\ ${ }^{1}$ Human Performance Laboratory, Department of Physical Education and Exercise Science, Auburn University at Montgomery, \\ Montgomery, USA; ${ }^{2}$ Exercise Physiology Laboratory, Department of Kinesiology, The University of Alabama, Tuscaloosa, USA. \\ Email: mesco@aum.edu
}

Received September $19^{\text {th }}, 2013$; revised October $17^{\text {th }}, 2013$; accepted November $12^{\text {th }}, 2013$

Copyright (C) 2013 Michael R. Esco et al. This is an open access article distributed under the Creative Commons Attribution License, which permits unrestricted use, distribution, and reproduction in any medium, provided the original work is properly cited.

\begin{abstract}
Background: The primary purpose of this investigation was to determine the differences in resting heart rate variability and heart rate recovery between norm-referenced aerobic fitness groupings, independent of body composition, in Black men. Additionally, we sought to clarify the independent relationships that heart rate variability and heart rate recovery displayed with maximal aerobic fitness and selected body composition measures. Methods: Body mass index, waist circumference, and the sum of skinfold thickness were determined in forty Black men ( $23 \pm 3$ years). Each subject assumed a supine position while heart rate variability was analyzed for 5-minute and recorded as normalized high-frequency power and normalized low-frequency power to normalized high frequency ratio. A graded exercise treadmill protocol was performed to attain maximal aerobic fitness. Heart rate recovery was recorded at 1- and 2-minute of a cool-down period. Heart rate variability and heart rate recovery were compared across two groups whose maximal aerobic fitness was either below or above the normative mean value for the age group of men. Results: The results indicated that heart rate variability was higher in the group whose maximal aerobic fitness was above the normative mean value compared with the lower fit group $(p<0.05)$, but the differences disappeared when adjusting for body composition $(p>0.05)$. Regression analysis revealed that the sum of skinfolds accounted for the variation in normalized high frequency power $\left(\mathrm{R}^{2}=0.20, p<0.05\right)$ and normalized low-frequency power to normalized high frequency ratio $\left(\mathrm{R}^{2}=\right.$ $0.30, p<0.05)$, while waist circumference accounted for the variation in heart rate recovery at 2 -minute $\left(\mathrm{R}^{2}=0.20, p<\right.$ 0.05 ). Conclusion: The results suggest that heart rate variability and heart rate recovery hold independent relationships to body composition but not aerobic fitness in young-adult, Black men.
\end{abstract}

Keywords: Skinfold Thickness; Waist Circumference; Cardiovascular; Autonomic

\section{Introduction}

Heart rate variability (HRV) and heart rate recovery (HRR) are two non-invasive measures of cardiovascularautonomic modulation [1-4]. HRV represents the autonomic controlled beat-to-beat oscillations that occur in heart rate, while HRR describes the parasympatheticmediated decline in heart rate immediately following exercise $[2,3]$. The clinical importance of both markers stands in their ability to independently predict untoward cardiac events and early development of cardiovascular disease $[2,4]$.

Recent evidence has suggested that HRV and HRR may reflect improved measures of physical fitness through lifestyle modification, yet the extent of this relationship remains unclear [5-7]. While several studies have indicated a possible link concerning aerobic fitness and body composition to HRV and HRR, much of the research emphasizes the relative importance of aerobic fitness. As a result, more research is needed to clarify the association of body composition with HRV and HRR [5,8-10].

Among the many factors contributing to disease states, the influence of race may be an important variable often overlooked. Accordingly, Blacks experience a greater prevalence of cardiovascular mortality compared with Whites $[11,12]$. Blacks also tend to be less physically active and have lower levels of aerobic fitness [12-14]. Research has indicated the existence of biological differences re- 
garding body composition between races [15]. Despite the apparent health disparities between racial groups, some investigators have shown greater HRV at rest and faster HRR following exercise in Blacks compared with Whites. However, the findings remain equivocal as others have presented conflicting data [16-19]. As such, the inconsistency of these results has led to speculations that the relationship between physical fitness and cardiacautonomic control may be race-dependent.

Furthermore, Esco et al. [10] showed that cardiovascular autonomic modulation is significantly related to maximal aerobic fitness and body composition. However, of the independent variables analyzed in the study, the sum of skinfold thickness appeared to have the strongest independent relationship with HRV and HRR, compared with other body composition parameters and maximal aerobic fitness [10]. Unfortunately, the study analyzed mostly white men [10]. Therefore, race-specific study in this area involving only Black men is needed. The results of such investigation could have important implications related to lifestyle interventions designed to reduce the risk of cardiovascular disease in this at-risk and understudied group.

The primary purpose of this investigation was to determine if differences in HRV and HRR would be reflected by norm-referenced aerobic fitness groupings, independent of body composition in young-adult Black men. Additionally, we sought to clarify the independent relationships that $\mathrm{HRV}$ and $\mathrm{HRR}$ display with $\mathrm{VO}_{2 \max }$ and selected body composition measures (e.g. body mass index [BMI], waist circumference [WC], and the sum of skinfold thickness [SF]) within the group.

\section{Materials and Methods}

\subsection{Study Sample}

Forty young-adult Black men participated in the study $($ age $=23 \pm 3$ years, height $=180.0 \pm 9.3 \mathrm{~cm}$, weight $=$ $82.8 \pm 11.2 \mathrm{~kg}$ ). Prior to study involvement, all subjects completed a health history questionnaire and were assessed to determine if they met inclusion criteria. All approved subjects were apparently healthy, free from cardiopulmonary, metabolic, and/or orthopedic impairments. At the time of data collection, all subjects were not taking any prescription or over-the-counter medications, each displaying normal blood pressure (i.e. $<140 /$ $90 \mathrm{mmHg}$ ). Subjects were non-smokers with normal electrocardiogram (ECG) readings, between the ages of 19 and 29 years, and self-reported race as Non-Hispanic/ Black over three generations. Written informed consent was obtained from each subject prior to study involvement. All research procedures were approved by the Institutional Review Board for Human Participants.

\subsection{Procedures}

All data were collected during a single visit to the laboratory. For convenience, each subject selected a 2-hour time slot on any day to complete the experimental procedures: from 7:00 AM and 9:00 AM, or from 9:00 AM and 11:00 AM. Subjects were instructed to avoid strenuous exercise for 24-h prior to the test, consumption of alcohol or sympathomimetic agents 12 hours before the test. Additionally, subjects were required not to eat at least 10 -h prior to data collection.

Height was measured with a wall-mounted stadiometer (SECA, Seca Instruments Ltd, Hamburg, Germany) and body weight was measured with a digital scale (TANITA BWB-800A, Tanita Corp, Tokyo, Japan) while the subjects stood erect without shoes. Body mass index (BMI) was determined as weight in kilograms divided by height in meters squared $\left(\mathrm{kg} \cdot \mathrm{m}^{-2}\right)$. Waist circumference was measured with a Gulick spring loaded handle (Mabis, Tokyo, Japan) in accordance with current American College of Sports Medicine (ACSM) recommendations [20].

Calibrated skinfold calipers (Harpenden; Baty International, West Sussex, United Kingdom) were used to measure the skinfold thickness from seven sites including: pectoralis major, triceps, mid-axillary region, subscapularis, suprailliac crest, abdomen, and thigh. The sum total of all measurements was recorded to the nearest $0.5 \mathrm{~mm}$. Additionally, all measurements followed ACSM guidelines [20].

Before the maximal exercise test, each subject was instructed to lay supine for a 10minutes on an athletic training table in a dimly lit climate controlled laboratory. Room temperature and humidity were maintained at approximately $22.2^{\circ} \mathrm{C}$ and $50 \%$, respectively. During this time, heart rate was assessed via ECG with the electrodes placed across the subject's chest in a modified Lead II arrangement. The electrode leads were connected to a Biopac MP100 data acquisition system (Goletta, CA, USA). All variables were stored for offline analysis. The ECG recordings were visually inspected and any ectopic/ non-sinus beats were removed and replaced by the adjacent normal cycle. If three or more ectopic beats were found within any ECG segment, the reading was excluded from analysis. The last 5 minute period of the ECG recording was used for HRV analysis.

The frequency domain analysis of HRV involved transforming the ECG into a power spectrum via fast Fourier transformation with a Hanning window by specialized HRV software (Nevrokard version 11.0.2, Izola, Slovenia). The areas under the high frequency (0.15 $0.40 \mathrm{~Hz})$ and low frequency $(0.04-0.14 \mathrm{~Hz})$ components of the power spectrum were normalized. Normalized high frequency (HFnu) was recorded to represent parasympathetic influence. Normalized low frequency to 
HFnu ratio (LF:HF) was recorded to represent sympathovagal balance. All HRV analyses were carried out in accordance with written established HRV guidelines [2].

All subjects completed a maximal graded exercise test using the Bruce protocol on a treadmill (Full Vision, Inc., Carrollton, TX). The concentration of expired oxygen and carbon dioxide gases were collected at the mouth with a pneumotach and analyzed using a calibrated Parvo Medics True One ${ }^{\circledR} 2400$ metabolic cart (Sandy, UT). Maximal oxygen uptake was determined if two of the following criteria occurred: a plateau in $\mathrm{VO}_{2}$ (within $\pm 2 \mathrm{ml} \cdot \mathrm{kg}^{-1} \cdot \mathrm{min}^{-1}$ ) despite an increasing work rate; respiratory exchange ratio $>1.15$; heart rate within 10 beats of age predicted ( $220-$ age) maximum or volitional fatigue. Once $\mathrm{VO}_{2 \max }$ was achieved, intensity was reduced to a speed of $1.5 \mathrm{mph}$ at $2 \%$ grade. HRR was determined as the difference between $\mathrm{HR}_{\max }$ and the heart rate recorded at 1- (HRR1) and 2-minute (HRR2) into recovery.

\subsection{Statistical Analysis}

Means and standard deviations were determined for all descriptive variables. The sample size was categorized into 2 groups based on whether they were below (AFG1, $\mathrm{n}=20)$ or above $(\mathrm{AFG} 2, \mathrm{n}=20)$ the value that corresponded to the referenced 50th percentile for $\mathrm{VO}_{2 \max }$ for college-age men: i.e., $43.9 \mathrm{ml} \cdot \mathrm{kg}^{-1} \cdot \mathrm{min}^{-1}$ [20].

One-way analysis of variance (ANOVA) procedures were used to compare HRV (i.e., HFnu and LF:HF) and HRR (i.e., HRR1 and HRR2) between AFG1 and AFG2. Follow-up analysis of covariance (ANCOVA) procedures were performed to control for the potential confounders of BMI, WC, and SF.

Zero-order correlations were also used to determine the relationship between the studied variables. To clarify the influence of $\mathrm{VO}_{2 \max }$ (as a continuous variable), BMI, WC, and SF on the variation in HFnu, LF:HF, HRR1, and HRR2, stepwise multiple regression procedures were used. The level of significance for all statistical tests was set at $p<0.05$ (SPSS/PASW version 18.0, Somers, NY).

\section{Results}

All participants successfully completed the testing procedures. Descriptive statistics for the complete sample are presented in Table 1. Mean values and significant group differences for $\mathrm{VO}_{2 \max }$, $\mathrm{BMI}, \mathrm{WC}, \mathrm{SF}$, HFnu, LF:HF, HRR1, and HRR2 are also displayed in Table 1. The one-way ANOVA procedures revealed significantly lower HFnu and significantly higher LF:HF values in AGF1 compared to AGF2 $(p<0.05$, Table 1). However, the one-way ANCOVA procedures showed that the differences in HFnu and LF:HF were not present when con- trolling for BMI ( $p=0.22, p=0.18$, respectively), WC ( $p$ $=0.12, p=0.11$, respectively, Table 1), and SF $(p=0.51$, $p=0.58$, respectively, Table 1).

Pearson product-moment correlations between all of the studied variables are shown in Table 2. $\mathrm{VO}_{2 \max }$ did not correlate with any HRV or HRR parameter $(p>0.05)$. BMI and SF were the only anthropometric variables to significantly correlate with either HFnu or LF:HF $(p<$ 0.05 ). Significant correlations were not found between any independent variable and HRR1 $(p>0.05)$. Only BMI and WC provided significant correlations with HRR2 $(p<0.05)$.

The stepwise regression procedures showed that SF was the only variable to significantly account for the

Table 1. Means and standard deviations of the studied variables within each group separately and the entire sample.

\begin{tabular}{cccc}
\hline & $\underline{A F G 1(n=20)}$ & $\underline{A F G 2(n=20)}$ & ALL $(\mathrm{n}=40)$ \\
\hline $\mathrm{VO}_{2 \max }$ & $39.13 \pm 3.15$ & $50.53 \pm 3.88^{*}$ & $44.83 \pm 6.75$ \\
$\mathrm{BMI}$ & $26.48 \pm 3.70$ & $24.57 \pm 2.37$ & $25.55 \pm 3.23$ \\
$\mathrm{WC}$ & $73.07 \pm 23.13$ & $58.80 \pm 25.47^{*}$ & $66.12 \pm 25.04$ \\
$\mathrm{SF}$ & $82.20 \pm 27.33$ & $56.65 \pm 20.72^{*}$ & $69.75 \pm 27.28$ \\
$\mathrm{HFnu}$ & $47.53 \pm 6.56$ & $52.25 \pm 7.61^{* \dagger}$ & $49.90 \pm 7.41$ \\
$\mathrm{LF}: \mathrm{HF}$ & $0.83 \pm 0.24$ & $0.65 \pm 0.27^{* \dagger}$ & $0.74 \pm 0.26$ \\
$\mathrm{HRR} 1$ & $21.60 \pm 6.00$ & $21.60 \pm 6.58$ & $21.60 \pm 6.22$ \\
$\mathrm{HRR} 2$ & $44.45 \pm 8.17$ & $43.10 \pm 10.26$ & $43.77 \pm 9.18$ \\
\hline
\end{tabular}

AFG1 = group of subjects with $\mathrm{VO}_{2 \max }$ values below the 50 th percentile normative value for age; $\mathrm{AFG} 2$ = group of subjects with $\mathrm{VO}_{2 \max }$ values above the 50th percentile normative value for age; $\mathrm{BMI}=$ body mass index; $\mathrm{WC}=$ waist circumference; $\mathrm{SF}=$ sum of skinfold thickness; $\mathrm{VO}_{2 \max }=$ maximal oxygen consumption; HFnu $=$ normalized high frequency $(\mathrm{HF})$ power; $\mathrm{LF}: \mathrm{HF}=$ low frequency power to HF power ratio; HRR1 = heart rate recovery at 1 -minute post-exercise; HRR2 $=$ heart rate recovery at 2-minute post-exercise. "Significantly different from AFG1 $(p<0.05)$. ${ }^{\dagger}$ The effect for SFG disappeared when controlling for BMI and SF (each separately).

Table 2. Zero-order correlation coefficients (r) showing the relationship between the variables.

\begin{tabular}{ccccc}
\hline & $\mathrm{VO}_{2 \max }$ & $\mathrm{BMI}$ & $\mathrm{WC}$ & $\mathrm{SF}$ \\
\hline HFnu & 0.27 & $-0.40^{\dagger}$ & -0.22 & $-0.46^{\dagger}$ \\
LF:HF & -0.25 & $0.45^{\dagger}$ & 0.29 & $0.54^{\dagger}$ \\
HRR1 & 0.08 & 0.13 & -0.09 & 0.12 \\
HRR2 & 0.03 & $0.37^{\dagger}$ & $0.44^{\dagger}$ & 0.29 \\
\hline
\end{tabular}

$\mathrm{VO}_{2 \max }=$ maximal oxygen consumption, $\mathrm{BMI}=$ body mass index, $\mathrm{WC}=$ waist circumference, $\mathrm{SF}=$ sum of skinfold thickness from 7-site, HRR1 = 1 -minute heart rate recovery, $\mathrm{HRR} 2=2$-minute heart rate recovery, $\mathrm{HFnu}=$ Normalized high frequency of heart rate variability, LF:HF = low frequency to high frequency ratio. ${ }^{\dagger}$ Significantly related, $p<0.01$. 
variation of HFnu $\left(\mathrm{R}^{2}=0.21, p<0.05\right)$ and LF:HF $\left(\mathrm{R}^{2}=\right.$ $0.30, p<0.05) . \mathrm{VO}_{2 \max }$, BMI, or WC did not contribute to the variation in HFnu $(p>0.05)$ or LF:HF $(p>0.05)$ and were not included in the models. Stepwise regression also revealed that WC was the only variable to significantly account for the variation in HRR2 $\left(\mathrm{R}^{2}=0.20\right)$. $\mathrm{VO}_{2 \max }$, BMI, or SF did not significantly contribute to the variation in HFnu $(p>0.05)$ and were not included in the model.

\section{Discussion}

The chronic effects of impaired cardiac-autonomic control exhibited as either lower HRV or delayed HRR can indicate the development of heart disease, hypertension, dyslipidemia, and type 2 diabetes $[21,22]$. These health conditions are prevalent at earlier ages in Blacks compared with other races [23-25]. Due to the discrepancies between races in cardiovascular disease risk factors, autonomic control and physical fitness [24,26,27] racespecific studies are needed.

The purpose of this study was to determine whether referenced aerobic fitness groupings would reflect differences in HRV and HRR, independent of selected anthropometric markers of body composition, and if the selected physical fitness parameters (i.e., $\mathrm{VO}_{2 \max }, \mathrm{BMI}$, $\mathrm{WC}$, and SF] were each significantly associated with the cardiac-autonomic variables in Black men.

According to the American College of Sports Medicine [20], the 50th percentile for $\mathrm{VO}_{2 \max }$ for the age group of the current sample is $43.9 \mathrm{ml} \cdot \mathrm{kg}^{-1} \cdot \mathrm{min}^{-1}$. The two groups were separated below (i.e., AFG1) and above (i.e., AFG2) this value. Though statistical significance was not found in HRR between groups, AFG1 had significantly lower HFnu and higher LF:HF compared to AFG2 indicating a less favorable autonomic balance in AFG1. However, the group differences in the HRV parameters were not present when markers of body composition were controlled for. In addition, BMI and SF were the only variables to be significantly related to HFnu and LF:HF. Alternatively, BMI and WC were the only variables to significantly correlate to HRR2. The stepwise regression procedures demonstrated that $\mathrm{SF}$ accounted for $21 \%$ and $30 \%$ of the variation in HFnu and LF:HF, respectively, and that $\mathrm{WC}$ accounted for $20 \%$ of the variation in HRR2. Therefore, SF seems to be the strongest predictor of resting HRV, while WC is the strongest predictor of HRR in Black men. When analyzed as a continuous variable, the stepwise regression procedures excluded $\mathrm{VO}_{2 \max }$ as it did not significant relate to any HRV or HRR parameter.

Previous investigations assessing the influence of aerobic fitness on cardiovascular-autonomic control have shown equivocal findings. Researchers suggest that training-induced bradycardia experienced by endurance athletes is caused by the increased parasympathetic tone [28]. However, others had claimed that this phenomenon was due to intrinsic, rather than extrinsic factors [29]. Still, some studies have suggested that there may $[5,30]$ or may not $[31,32]$ be an independent association between increases in aerobic fitness and enhanced HRR or HRV. Furthermore, there does not appear to be a significant difference in HRV and HRR between aerobicallytrained and anaerobically-trained athletes [33,34]. As such, it seems reasonable to propose that other components of physical fitness may play a role in enhancing cardiovascular-autonomic control rather than just increased $\mathrm{VO}_{2 \max }$.

Body composition is a parameter of physical fitness that appears to be independently linked to autonomic activity. Increased adiposity is thought to contribute to heightened sympathetic nervous activity at rest, while blunting metabo- and baro-reflex sensitivity during and following exercise $[24,35,36]$. Studies have shown that WC, BMI, and body fat percentage are each negatively associated with HRV and HRR $[9,10,37]$. Similar to the current study, Esco and colleagues [10] showed that SF explained the greatest variation of HRV and HRR when analyzed via stepwise regression. However, separating independent variables from their study, including $\mathrm{VO}_{2 \max }$, did not add statistical significance to either model. Interestingly though, the sample consisted of mostly White men [10].

The novelty of the current investigation highlights the relationship between selected markers of physical fitness and cardiovascular-autonomic modulation in Black men. We believe that this is an important area of research due to the higher prevalence of cardiac-related disorders in Blacks, and due to the discrepancies in physical fitness and cardiovascular autonomic control between races [13, $14,16,18,19]$. Similar to other studies [10,18], it appears that the difference in HRV across groups based on $\mathrm{VO}_{2 \max }$ in Black men may be due to the fitter subjects having a healthier body composition profile.

Significant HRR differences were not found between AGF1 and AGF2. The post-exercise autonomic marker, HRR2, was significantly and independently related to WC, but not SF or $\mathrm{VO}_{2 \max }$. This result is at odds with previous research conducted by Esco et al. [10] who showed HRR to be significantly related to SF, but not WC in mainly White men. Conversely, Gutin et al. [18] showed that WC had a negative influence on sympathetic-to-parasympathetic balance in Black adolescents, but not compared to their White counterparts. Interestingly, some studies suggest a higher HRV profile and faster HRR post-exercise in Blacks compared to Whites, 
despite Blacks having lower levels of cardiovascular fitness and higher rates of obesity $[18,38,39]$. One way to interpret these paradoxical findings is that the relationship between body composition, aerobic fitness and cardiac-autonomic control is race-specific. Nevertheless, the current findings strengthen the usefulness of simple body composition measures in predicting cardiovascular disease risk factors in Black men at any level of aerobic fitness.

The age of the current sample should be considered when interpreting the results, as only apparently healthy, young adult Black men were analyzed. Aging has been shown to affect cardiovascular-autonomic control and physical fitness. More specifically, Blacks have been shown having a more favorable autonomic profile in younger years of age [18]. However, these patterns may become confounded with aging due to the influence and higher prevalence of obesity or markers of inflammation in Blacks [18,40,41]. Accordingly, similar investigations that include older aged subjects and other ethnic/racial groups are needed to better understand this relationship.

In conclusion, this study provided a direct comparison of HRV and HRR in young Black men with differing levels of aerobic fitness. The results of the investigation suggested higher HRV with a higher level of aerobic fitness in Black men primarily because of the fitter group having a superior body composition profile compared to the lower fit group. Skinfold thickness was the greatest predictor of resting HRV. Heart rate recovery did not differ from high fit and low fit groups, but was significantly related to WC. The results of this study underscore the importance of body composition when explaining the relationship between physical fitness and cardiovascular-autonomic control in young Black men. According to these results, lifestyle interventions should be designed to improve aerobic fitness and body composition to fully enhance cardiovascular-autonomic function to mitigate risk for an acute cardiac event. Additional research is needed to further define the relationship between physical fitness and cardiovascular-autonomic modulation, thus aiding clinicians to provide appropriate lifestyle modifications to lower at-risk populations for cardiovascular disease.

\section{REFERENCES}

[1] M. R. Esco, M. S. Olson, H. N. Williford, D. L. Blessing, D. Shannon and P. Grandjean, "The Relationship between Resting Heart Rate Variability and Heart Rate Recovery," Clinical Autonomic Research, Vol. 20, No. 1, 2010, pp. 33-38. http://dx.doi.org/10.1007/s10286-009-0033-2

[2] A. J. Camm, M. Malik, J. T. Bigger, G. Breithardt, S. Cerutti, R. J. Cohen, P. Coumel, E. L. Fallen, H. L. Kennedy, R. E. Kleiger, F. Lombardi, A. Malliani, A. J. Moss,
J. N. Rottman, G. Schmidt, P. J. Schwartz and D. H. Singer, "Heart Rate Variability: Standards of Measurement, Physiological Interpretation and Clinical Use. Task Force of the European Society of Cardiology and the North American Society of Pacing and Electrophysiology," Circulation, Vol. 93, No. 5, 1996, pp. 1043-1065.

[3] K. Imai, H. Sato, M. Hori, H. Kusuoka, H. Ozaki, H. Yokoyama, H. Takeda, M. Inoue and T. Kamada, "Vagally Mediated Heart Rate Recovery after Exercise Is Accelerated in Athletes but Blunted in Patients with Chronic Heart Failure," Journal of the American College of Cardiology, Vol. 24, No. 6, 1994, pp. 1529-1535. http://dx.doi.org/10.1016/0735-1097(94)90150-3

[4] C. R. Cole, E. H. Blackstone, F. J. Pashkow, C. E. Snader and M. S. Lauer, "Heart-Rate Recovery Immediately after Exercise as a Predictor of Mortality," New England Journal of Medicine, Vol. 341, No. 18, 1999, pp. 1351-1357. http://dx.doi.org/10.1056/NEJM199910283411804

[5] A. E. Aubert, B. Seps and F. Beckers, "Heart Rate Variability in Athletes," Sports Medicine, Vol. 33, No. 12, 2003, pp. 889-919. http://dx.doi.org/10.2165/00007256-200333120-00003

[6] M. Buchheit and C. Gindre, "Cardiac Parasympathetic Regulation: Respective Associations with Cardiorespiratory Fitness and Training Load," American Journal of Physiology-Heart and Circulatory Physiology, Vol. 291, No. 1, 2006, pp. H451-H458.

http://dx.doi.org/10.1152/ajpheart.00008.2006

[7] P. Buch, J. Friberg, H. Scharling, P. Lange and E. Prescott, "Reduced Lung Function and Risk of Atrial Fibrillation in the Copenhagen City Heart Study," European Respiratory Journal, Vol. 21, No. 6, 2003, pp. 1012-1016. http://dx.doi.org/10.1183/09031936.03.00051502

[8] R. M. Millis, R. E. Austin, M. D. Hatcher, V. Bond, M. U. Faruque, K. L. Goring, B. M. Hickey and R. E. DeMeersman, "Association of Body Fat Percentage and Heart Rate Variability Measures of Sympathovagal Balance," Life Sciences, Vol. 86, No. 5, 2010, pp. 153-157. http://dx.doi.org/10.1016/j.1fs.2009.11.018

[9] E. Z. Campos, F. N. Bastos, M. Papoti, I. F. Freitas Jr., C. A. Gobatto and P. Balikian Jr., "The Effects of Physical Fitness and Body Composition on Oxygen Consumption and Heart Rate Recovery after High-Intensity Exercise," International Journal of Sports Medicine, Vol. 33, No. 8, 2012, pp. 621-626. http://dx.doi.org/10.1055/s-0031-1295442

[10] M. R. Esco, H. N. Williford and M. S. Olson, "Skinfold Thickness Is Related to Cardiovascular Autonomic Control as Assessed by Heart Rate Variability and Heart Rate Recovery," Journal of Strength and Conditioning Research, Vol. 25, No. 8, 2011, pp. 2304-2310. http://dx.doi.org/10.1519/JSC.0b013e3181f90174

[11] S. B. Richards, M. Funk and K. A. Milner, "Differences between Blacks and Whites with Coronary Heart Disease in Initial Symptoms and in Delay in Seeking Care," American Journal of Critical Care, Vol. 9, No. 4, 2000, pp. 237-244.

[12] E. J. Bell, P. L. Lutsey, B. G. Windham and A. R. Folsom, 
"Physical Activity and Cardiovascular Disease in African Americans in Atherosclerosis Risk in Communities," Medicine and Science in Sports and Exercise, Vol. 45, No. 5, 2013, pp. 901-907.

http://dx.doi.org/10.1249/MSS.0b013e31827d87ec

[13] M. Bopp, S. Wilcox, M. Laken, K. Butler, R. E. Carter, L. McClorin and A. Yancey, "Factors Associated with Physical Activity among African-American Men and Women," American Journal of Preventative Medicine, Vol. 30, No. 4, 2006, pp. 340-346. http://dx.doi.org/10.1016/j.amepre.2005.11.007

[14] C. J. Lavie, T. Kuruvanka, R. V. Milani, A. Prasad and H. O. Ventura, "Exercise Capacity in Adult African-Americans Referred for Exercise Stress Testing: Is Fitness Affected by Race?” CHEST Journal, Vol. 126, No. 6, 2004, pp. 1962-1968.

http://dx.doi.org/10.1378/chest.126.6.1962

[15] D. R. Wagner and V. H. Heyward, "Measures of Body Composition in Blacks and Whites: A Comparative Review," American Journal of Clinical Nutrition, Vol. 71, No. 6, 2000, pp. 1392-1402.

[16] M. R. Carnethon, B. Sternfeld, K. Liu, D. R. Jacobs Jr., P. J. Schreiner, O. D. Williams, C. E. Lewis and S. Sidney, "Correlates of Heart Rate Recovery over 20 Years in a Healthy Population Sample," Medicine and Science in Sports and Exercise, Vol. 44, No. 2, 2012, pp. 273-279. http://dx.doi.org/10.1249/MSS.0b013e31822cb190

[17] R. P. Sloan, M. H. Huang, S. Sidney, K. Liu, O. D. Williams and T. Seeman, "Socioeconomic Status and Health: Is Parasympathetic Nervous System Activity an Intervening Mechanism?" International Journal of Epidemiology, Vol. 34, No. 2, 2005, pp. 309-315. http://dx.doi.org/10.1093/ije/dyh381

[18] B. Gutin, C. Howe, M. H. Johnson, M. C. Humphries, H. Snieder and P. Barbeau, "Heart Rate Variability in Adolescents: Relations to Physical Activity, Fitness, and Adiposity," Medicine and Science in Sports and Exercise, Vol. 37, No. 11, 2005, pp. 1856-1863. http://dx.doi.org/10.1249/01.mss.0000175867.98628.27

[19] X. Wang, J. F. Thayer, F. Treiber and H. Snieder, "Ethnic Differences and Heritability of Heart Rate Variability in African- and European-American Youth," American Journal of Cardiology, Vol. 96, No. 8, 2005, pp. 1166-1172. http://dx.doi.org/10.1016/j.amjcard.2005.06.050

[20] W. R. Thompson, N. F. Gordon and L. S. Pescatello, "ACSM's Guidelines for Exercise Testing and Prescription," 8th Edition, Lippincott Williams and Wilkins, Philadelphia, 2010.

[21] C. Voulgari, S. Pagoni, A. Vinik and P. Poirier, "Exercise Improves Cardiac Autonomic Function in Obesity and Diabetes," Metabolism, Vol. 62, No. 5, 2012, pp. 609621.

[22] J. S. Wu, Y. C. Yang, F. H. Lu, T. S. Lin, J. J. Chen, Y. H. Huang, T. L. Yeh and C. J. Chang, "Cardiac Autonomic Function and Insulin Resistance for the Development of Hypertension: A Six-Year Epidemiological Follow-Up Study," Nutrition, Metabolism and Cardiovascular Disease, 2013.
[23] K. Bibbins-Domingo, M. J. Pletcher, F. Lin, E. Vittinghoff, J. M. Gardin, A. Arynchyn, C. E. Lewis, O. D. Williams and S. B. Hulley, "Racial Differences in Incident Heart Failure among Young Adults," New England Journal of Medicine, Vol. 360, No. 12, 2009, pp. 1179-1190. http://dx.doi.org/10.1056/NEJMoa0807265

[24] W. M. Sherman, A. L. Katz, C. L. Cutler, R. T. Withers and J. L. Ivy, "Glucose Transport: Locus of Muscle Insulin Resistance in Obese Zucker Rats," American Journal of Physiology, Vol. 255, No. 3, 1988, pp. E374-E382.

[25] D. R. Williams and J. Leavell, "The Social Context of Cardiovascular Disease: Challenges and Opportunities for the Jackson Heart Study," Ethnicity and Disease, Vol. 22, No. 1, 2012, pp. S1-S14.

[26] C. J. Lavie, T. Kuruvanka, R. V. Milani, A. Prasad and H. O. Ventura, "Exercise Capacity in Adult African-Americans Referred for Exercise Stress Testing: Is Fitness Affected by Race?" CHEST Journal, Vol. 126, No. 6, 2004, pp. 1962-1968. http://dx.doi.org/10.1378/chest.126.6.1962

[27] D. Liao, R. W. Barnes, L. E. Chambless, R. J. Simpson Jr., P. Sorlie and G. Heiss, "Age, Race, and Sex Differences in Autonomic Cardiac Function Measured by Spectral Analysis of Heart Rate Variability-The ARIC Study," American Journal of Cardiology, Vol. 76, No. 12, 1995, pp. 906-912. http://dx.doi.org/10.1016/S0002-9149(99)80260-4

[28] J. B. Carter, E. W. Banister and A. P. Blaber, "Effect of Endurance Exercise on Autonomic Control of Heart Rate," Sports Medicine, Vol. 33, No. 1, 2003, pp. 33-46. http://dx.doi.org/10.2165/00007256-200333010-00003

[29] A. S. Scott, A. Eberhard, D. Ofir, G. Benchetrit, T. P. Dinh, P. Calabrese, V. Lesiuk and H. Perrault, "Enhanced Cardiac Vagal Efferent Activity Does Not Explain Training-Induced Bradycardia," Autonomic Neuroscience, Vol. 112, No. 1, 2004, pp. 60-68. http://dx.doi.org/10.1016/j.autneu.2004.04.006

[30] A. Aslani, A. Aslani, J. Kheirkhah and V. Sobhani, "CardioPulmonary Fitness Test by Ultra-Short Heart Rate Variability," Journal of Cardiovascular Disease Research, Vol. 2, No. 4, 2011, pp. 233-236. http://dx.doi.org/10.4103/0975-3583.89808

[31] E. A. Byrne, J. L. Fleg, P. V. Vaitkevicius, J. Wright and S. W. Porges, "Role of Aerobic Capacity and Body Mass Index in the Age-Associated Decline in Heart Rate Variability," Journal of Applied Physiology, Vol. 81 No. 2, 1996, pp. 743-750.

[32] B., Verheyden, B. O. Eijnde, F. Beckers, L. Vanhees and A. E. Aubert, "Low-Dose Exercise Training Does Not Influence Cardiac Autonomic Control in Healthy Sedentary Men Aged 55-75 Years," Journal of Sports Science, Vol. 24, No. 11, 2006, pp. 1137-1147. http://dx.doi.org/10.1080/02640410500497634

[33] T. Otsuki, S. Maeda, M. Iemitsu, Y. Saito, Y. Tanimura, J. Sugawara, R. Ajisaka and T. Miyauchi, "Postexercise Heart Rate Recovery Accelerates in Strength-Trained Athletes," Medicine and Science in Sports and Exercice, Vol. 39, No. 2, 2007, pp. 365-370. 
http://dx.doi.org/10.1249/01.mss.0000241647.13220.4c

[34] D. J. Berkoff, C. B. Cairns, L. D. Sanchez and C. T. Moorman III, "Heart Rate Variability in Elite American Track-and-Field Athletes," Journal of Strength and Conditioning Research, Vol. 21, No. 1, 2007, pp. 227-231. http://dx.doi.org/10.1519/00124278-200702000-00041

[35] K. Dipla, G. P. Nassis and I. S. Vrabas, "Blood Pressure Control at Rest and during Exercise in Obese Children and Adults," Journal of Obesity, Vol. 2012, 2012, pp. 1-10. http://dx.doi.org/10.1155/2012/147385

[36] A. Figueroa, T. Baynard, B. Fernhall, R. Carhart and J. A. Kanaley, "Impaired Postexercise Cardiovascular Autonomic Modulation in Middle-Aged Women with Type 2 Diabetes," European Journal of Cardiovascular Prevention and Rehabilitation, Vol. 14, No. 2, 2007, pp. 237243. http://dx.doi.org/10.1097/HJR.0b013e32801da10d

[37] F. Deniz, M. T. Katircibasi, B. Pamukcu, S. Binici and S. Y. Sanisoglu, "Association of Metabolic Syndrome with Impaired Heart Rate Recovery and Low Exercise Capacity in Young Male Adults," Clincal Endocrinolgy, Vol. 66, No. 2, 2007, pp. 218-223. http://dx.doi.org/10.1111/j.1365-2265.2006.02711.x

[38] M. R. Esco and M. S. Olson, "Racial Differences Exist in Cardiovascular Parasympathetic Modulation Following
Maximal Exercise," Journal of Applied Research, Vol. 10, No 1, 2010, pp. 24-31.

[39] K. M. Flegal, M. D. Carroll, C. L. Ogden and L. R. Curtin, "Prevalence and Trends in Obesity Among US Adults, 1999-2008," Journal of the American Medical Association, Vol. 303, No. 3, 2010, pp. 235-241. http://dx.doi.org/10.1001/jama.2009.2014

[40] D. S. Freedman, L. K. Khan, M. K. Serdula, D. A. Galuska and W. H. Dietz, "Trends and Correlates of Class 3 Obesity in the United States from 1990 through 2000," Journal of the American Medical Association, Vol. 288, No. 14, 2002, pp. 1758-1761.

http://dx.doi.org/10.1001/jama.288.14.1758

[41] K. S. Heffernan, S. Y. Jae, V. J. Vieira, G. A. Iwamoto, K. R. Wilund, J. A. Woods and B. Fernhall, "C-Reactive Protein and Cardiac Vagal Activity Following Resistance Exercise Training in Young African-American and White Men," American Journal of Physiology-Regulatory, Integrative and Comparative Physiology, Vol. 296, No. 4, 2009, pp. R1098-R1105.

http://dx.doi.org/10.1152/ajpregu.90936.2008 